\title{
STRUCTURAL AND ELECTRICAL PROPERTIES OF SNS THIN FILMS VIA CHEMICAL BATH DEPOSITION TECHNIQUE
}

\author{
P. sateesh $^{1}$ and P. Madhusudhanarao ${ }^{2}$
}

Abstract: Nano crystalline semiconducting materials have attracted a great deal of attention because of their size dependent property and wide range of applications. $\mathrm{SnS}$ is one of the most interesting semiconducting materials. In the present work, semiconducting $\mathrm{SnS}$ Nano thin films were grown on microscope glass substrate using solution growth technique from solutions of triethanolamine (TEA), ammonia $\left(\mathrm{NH}_{3}\right)$ and thioacetamide (TA). The method is relatively simple easy to control, sufficient to produce large area and good adherence to the substrate films. The properties of the films grown at different temperatures with different concentrations were characterized using various techniques.

Keywords: Chemical bath deposition; SnS; thin films; properties.

\section{INTRODUCTION}

The IV-VI group of semiconductors has a significant role to play in the fabrication of photovoltaic devices because of their suitable characteristics like high optical transmittance, absorbance, energy band gap and control over electrical properties. Among them tin monosulphide $(\mathrm{SnS})$ has attracted considerable attention in recent years .Tin monosulphide $(\mathrm{SnS})$ plays a unique role due to its energy band gap of $1.35 \mathrm{eV}$ close to optimum value 1.5 $\mathrm{eV}$ for maximum absorption of solar radiation. The lattice structure of $\mathrm{SnS}$ is closely related to the black phosphorous structure. Tin sulphide $(\mathrm{SnS})$ is having orthorhombic crystal structure with eight atoms per unit Cell. The cation $(\mathrm{Sn})$ and anion $(\mathrm{S})$ double layers made-up of two planes of zigzag cation - anion chains are perpendicular to the longest crystallographic axis. The compound $\mathrm{SnS}$ is a semiconductor with a band gap of $1.3 \mathrm{ev}$ with the potential to become a versatile solar energy material. The narrow band and interesting Structural properties of SnS satisfy most of the criterion to make them potential candidate in photo electro chemical solar cell as thin film absorber and thin film solar cells near infrared detector such as photovoltaic Materials in optoelectronic systems. SnS is the one of the promising materials for low cost thin film Solar technology due to its optimum energy gap, a high fundamental absorption coefficient, non toxicity and abundance. For the deposition of $\mathrm{SnS}$ thin films, various methods like spray pyrolysis, electro deposition Magnetron sputtering, vacuum evaporation and chemical bath deposition are employed. Among these methods CBD is Very simple more rapid and inexpensive method suitable for deposition on large substrates irrespective of the shape and morphology of substrates near at room temperature

\footnotetext{
${ }^{1}$ Research Scholar, Department of Physics, Sree Dattha institute of Engineering and Science, $\quad$ Hyderabad, Telangana State, India

${ }^{2}$ Professor of Physics, BVRITH College of Engineering for women, Hyderabad, Telangana State, India
} 


\section{EXPERIMENTAL DETAILS}

Reagents used: stannous chloride (98.5\% purity), thioacetamide (98.5\% purity) are purchased from finar chemicals. Glacialaceticacid, triethanolamine, HCL and ammonia are Purchased from Aldrich

\section{Materials and method}

Optical microscope slide with the size of $25.4 \mathrm{~mm} \times 76.2 \mathrm{~mm}$ and $1.2 \mathrm{~mm}$ thick was an important substrate used to deposit thin films of material. The substrate was prepared and cleaned by the following method . First it was immersed in to the beaker that filled with nitric acid for 48hours. After the microscope slide immersed into the beaker that contained deionized water it was degreased for 20 minutes by using dryer. Later it was immersed in to the beaker that filled with ethanol and then degreased 20 minutes by using the dryer.Then the microscope slide was taken out and rinsed in deionized water. Finally it was ready to heated in the oven for about 15 mins at $100^{\circ} \mathrm{C}$.

\section{Experimental Method}

In this study specified amount of stannous chloride was weighed into a100ml beaker in order to prepare various concentrations of $\mathrm{SnCl}_{2}$ solution $(0.1,0.3 \& 0.5 \mathrm{M})$. Then about $2 \mathrm{ml}$ of glacial acetic acid was added to dissolve the Stannous chloride taken in a beaker and heated at $410 \mathrm{k}$ with stirring for $10 \mathrm{~min}$ on a hot plate followed by the addition of $1 \mathrm{ml}$ of $\mathrm{HCL}$ resulting in a clear transparent solution to a $100 \mathrm{ml}$ beaker. After that $30 \mathrm{ml}$ triethanolamine $\left(\mathrm{C}_{6} \mathrm{H}_{15} \mathrm{No}_{3}\right)$ (as supplied diluted to $\left.50 \%\right) 16 \mathrm{ml}$ ammonia $\left(\mathrm{NH}_{4} \mathrm{OH}\right), 10 \mathrm{ml}$ thioacetamide (TA) $(0.1 \mathrm{M}, 0.3 \& 0.5 \mathrm{M})$ of experimental design was added in to the same beaker and the mixture solutions were again stirred. Among this experiment ammonia was added to change the $\mathrm{PH}$ in to certain values (PH 9.20, 9.19\&8.76) using PH meter. Later the solution poured into another beaker containing clean glass substrate, clamped vertically. The deposition is made at room temperature, the bath colour leaving a clear red to a permanently chocolate brown. SnS films nucleated on to submerged surfaces, including beaker walls in about $24 \mathrm{~h}$ for one deposition run. At the end of each deposition run, the layer is rinsed in bid stilled water. The sample was preserved in the desiccators for 2-3days and kept for further analysis.

In order to investigate the crystallographic properties of the tin sulphide thin films we carried out the x-ray diffraction analysis using CINEL XRG 300 X-ray diffractometer with $\mathrm{CuK} \alpha$ radiation. The surface morphology was observed by a scanning electron microscopy (JEOL, JSM-6400), at $15 \mathrm{kV}$ with a $25.00 \mathrm{KX}$ magnification.

\section{RESULTS AND DISCUSSION}

Chemical deposition method is based on a chemical reaction between dissolved precursors in aqueous solution. Tin sulphide films were deposited on microscope slide from bath solution which contains stannous chloride, glacial acetic acid, tri-ethanol amine and thioacetamide. Stannous chloride and thioacetamide were used to provide the tin ions and sulphur ions respectively. Mean while triethanolamine was used as the complex agent to prolong the life time of the long deposition bath besides enhancing the adhesion of the deposition films on the optical microscope slide. Analysis of the data given in table1reveal that the films deposited using $0.1 \mathrm{~m} \mathrm{Sncl}_{2}$ produce thinner films while higher concentration $\mathrm{Sncl}_{2}$ solution $(0.3 \mathrm{~m})$ produce thin films. 
Films prepared using higher concentration $(0.5 \mathrm{M})$ of thioacetamide produce thinner films than that prepared using $(0.1 \mathrm{~m}, 0.3 \mathrm{~m} \& 0.5 \mathrm{~m})$ of thioacetamide. At the shorter deposition time a very thin layer of films could be formed. This indicates that prolonged deposition time is suitable for the chemical bath deposition of SnS films. It also indicates the preferential orientated growth of SnS nanoparticles, nanorods and nanosheets. Further, it is found that the intensity of the crystalline peaks improved with an increasing in the reaction time and high intensity plane for the orthorhombic $\mathrm{SnS}$ structure. For the prolonged reaction time such as 24 hours and 48 hours, only single phase (orthorhombic crystal structure) SnS nanostructures were formed without impurities like sodium tin sulfide, $\mathrm{SnS}_{2}$ and $\mathrm{SnO}_{2}$.

Table 1:The results of the PH values of the 4 samples that were obtained in this experiment

\begin{tabular}{|l|l|l|l|}
\hline S.NO. & PH & $\begin{array}{l}\text { Concentration of } \\
\mathbf{S n C l}_{2}(\mathbf{M})\end{array}$ & $\begin{array}{l}\text { Concentration } \\
\text { Thioacetamide ( M ) }\end{array}$ \\
\hline 1 & 9.20 & 0.1 & 0.1 \\
\hline 2 & 9.19 & 0.3 & 0.3 \\
\hline 3 & 8.76 & 0.5 & 0.5 \\
\hline 4 & 8.82 & 0.5 & 0.3 \\
\hline
\end{tabular}

\section{Structural Analysis}

$\mathbf{X}$ - ray diffraction patterns of the films deposited at different concentrations $(0.1 \mathrm{M}, 0.3 \mathrm{M} \&$ $0.5 \mathrm{~m}$ ) for all films are recorded. The observed peaks were analyzed and indexed using standard pattern for the Mineral Herzenbergite with orthorhombic structured SnS (JCPDS PDF Card \# 39-0354). The analysis of the XRD pattern of films deposited after 24h indicate the formation of a poorly crystalline film. In order to study the structure of the films, X-ray diffraction (XRD) analysis was performed on sample 1and sample 2.Table 2 shows the comparison between the experimental and standard values for sample 1 and sample 2 . The peaks observed in Fig.(1) and Fig.(2) at $2 \theta$ values of $32.85^{0}, 45.85^{\circ} 54.95^{\circ}$ and $75.75^{\circ}$ were found to match with reflections from (200), (220), (311) and (331) crystallographic planes of orthorhombic phase of SnS Respectivitely. The average crystalline size is estimated by

Sherer formula: $\mathrm{D}=\mathrm{K} \lambda / \beta \cos \theta$

Where $\lambda$ is the wavelength of $\mathrm{CuK} \alpha$ radiation $(0.154 \mathrm{~nm}), \mathrm{k}=0.9$ is the shape factor, $\theta$ is the Bragg angle and $\beta$ is the experimental full-width at half maximum on the respective diffraction peak. The

The micro strain $\varepsilon$ can be obtained by using the relation

$\varepsilon=\beta \cos \theta / 4$

From the below table shows the average crystalline size of different samples is about $36.28 \mathrm{~nm}$ 


\section{Thickness of the samples}

The cross-section of SEM gives different thickness of different concentrations of samples.

Table2: Comparison between experimental and standard data values of X-ray diffraction for sample $1(0.1 \mathrm{M})$ sample $2(0.3 \mathrm{M})$ and sample $3(0.5 \mathrm{M})$

\begin{tabular}{|c|c|c|}
\hline \multicolumn{2}{|l|}{$2 \theta$} & \multirow[b]{2}{*}{ hkl } \\
\hline Observed values & Jcpds data & \\
\hline 32.85 & 32.87 & 200 \\
\hline 45.85 & 47.17 & 220 \\
\hline 54.95 & 55.17 & 311 \\
\hline 75.75 & 76.14 & 331 \\
\hline 54.55 & 57.17 & 311 \\
\hline 57.25 & 57.17 & 311 \\
\hline
\end{tabular}

Table 3: The peak position (20), full width at half maximum (FWHM, $\beta$ ) value, $d$ value, average crystallite size (D), and micro-strain

\begin{tabular}{|l|l|l|l|l|l|l|l|}
\hline $\begin{array}{l}\text { S.no } \\
\text { ation } \\
\text { ationcentr }\end{array}$ & Thickness & $\begin{array}{l}\text { Peak } \\
\text { position }\end{array}$ & FWHM & hkl & $\begin{array}{l}\text { Average } \\
\text { crystalline } \\
\text { size } \\
(\mathbf{n m})\end{array}$ & $\begin{array}{l}\text { Micro } \\
\text { strain } \\
(\mathbf{1 0}\end{array}$ \\
\hline 1 & 0.1 & 130 & 32.85 & 0.65 & 200 & 29.06 & 1.2 \\
\hline 2 & 0.3 & 132 & 54.95 & 0.65 & 311 & 31.01 & 0.6 \\
& & & 75.75 & 0.63 & 331 & 21.95 & 1.1 \\
\hline
\end{tabular}




\begin{tabular}{|l|l|l|l|l|l|l|l|}
\hline 3 & 0.5 & 135 & 54.55 & 0.60 & 311 & 43.31 & 0.8 \\
& & & 57.25 & 0.40 & 311 & 37.41 & 0.9 \\
\hline
\end{tabular}

Figure 1: X-ray diffraction pattern of sns (0.3M) thin film grown
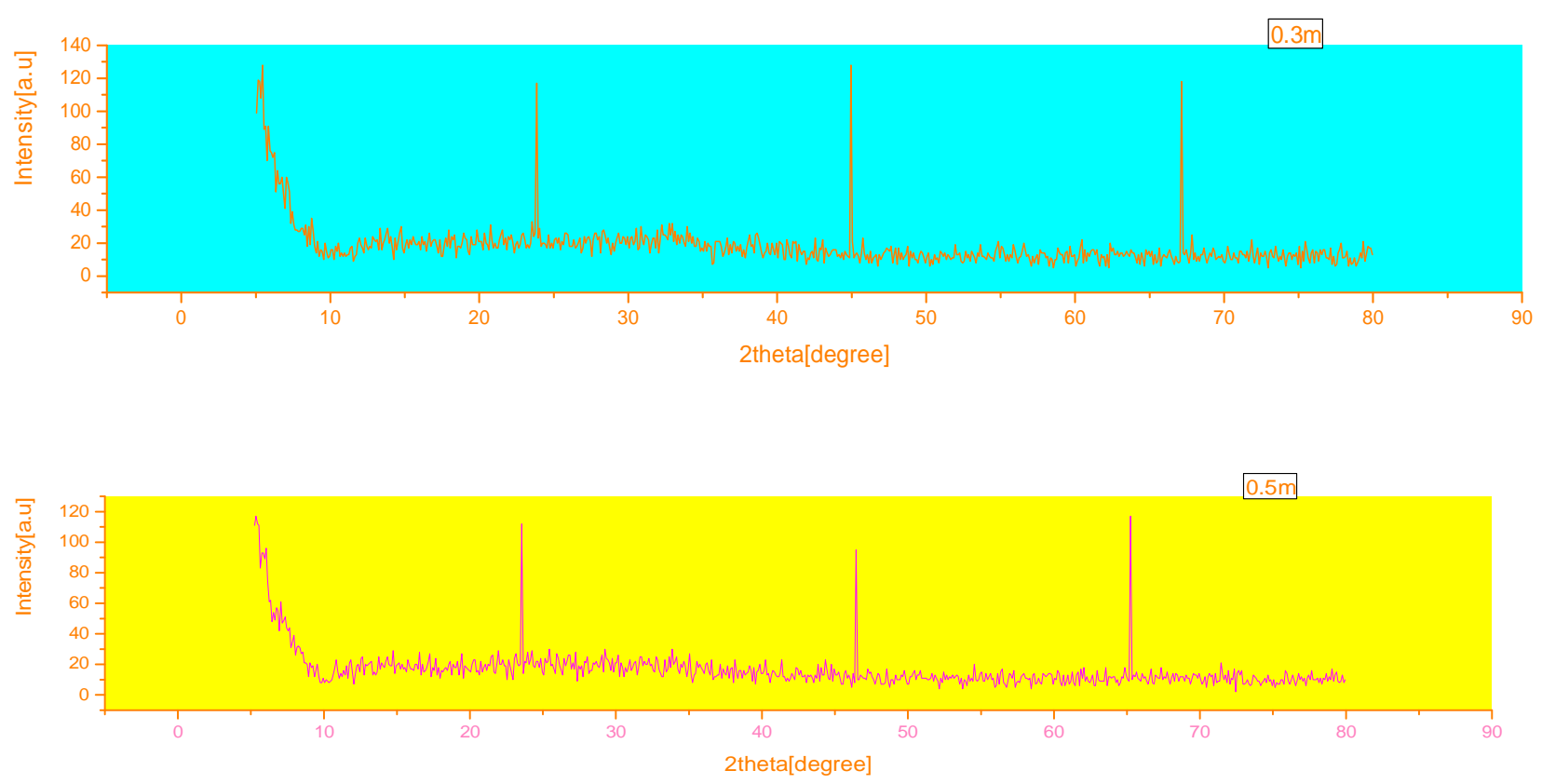

Figure2: X-ray diffraction pattern of $\mathrm{SnS}(0.5 \mathrm{M})$ thin film grown

Fig 3: Concentration of different thickness samples

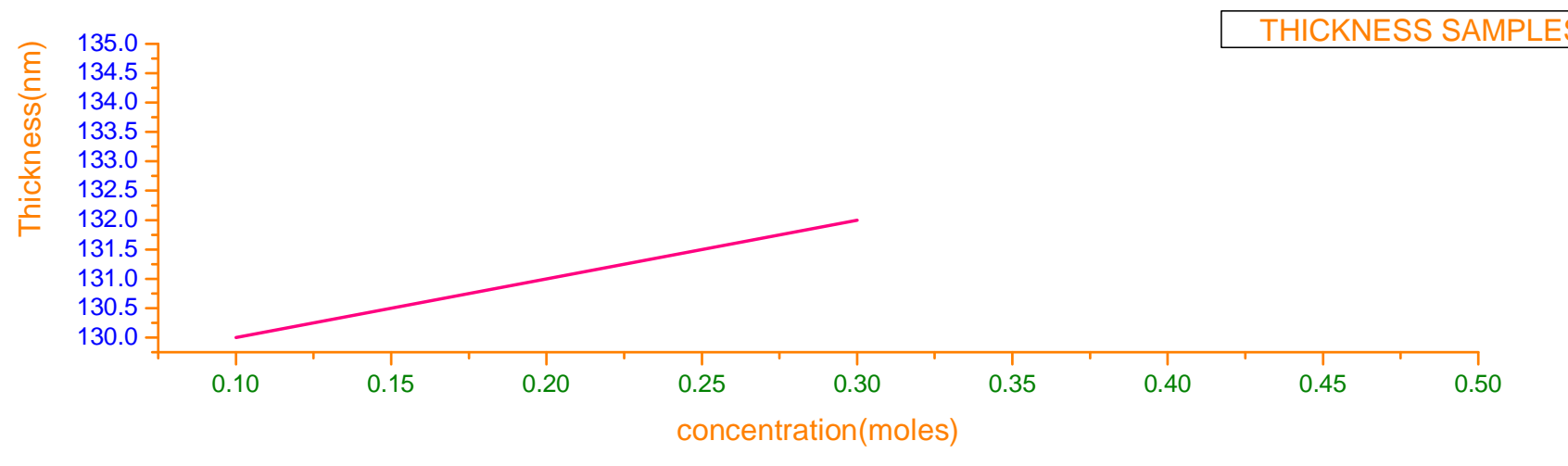

Fig 3 shows, as the concentration of the sample increases the thickness of the sample also increases. There is a rapid growth in thickness of the sample in between the values of 0.15 to 0.30 .

Fig 4: the variation of FWHM with concentration of samples 


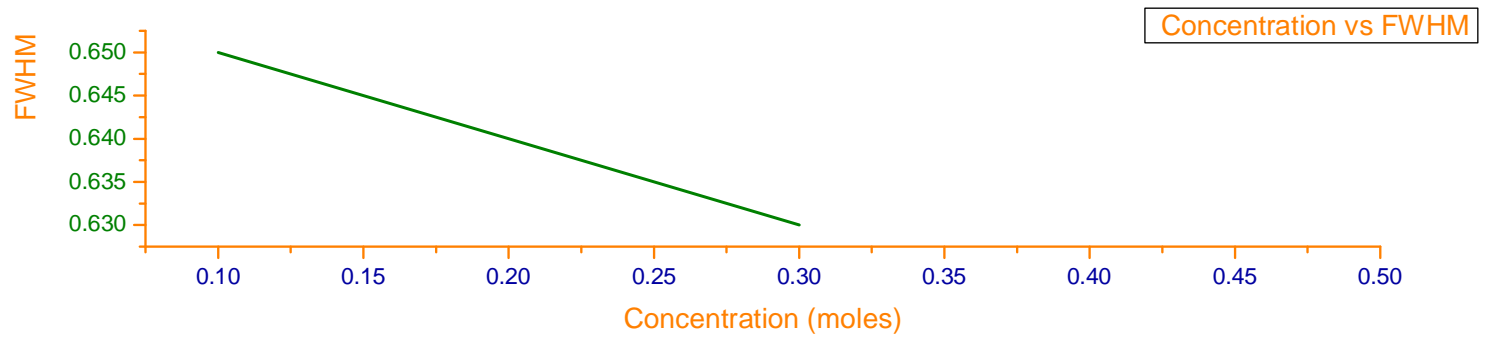

Fig 4 SHOWS, AS THE CONCENTRATION INCREASES, FWHM DECREASES.

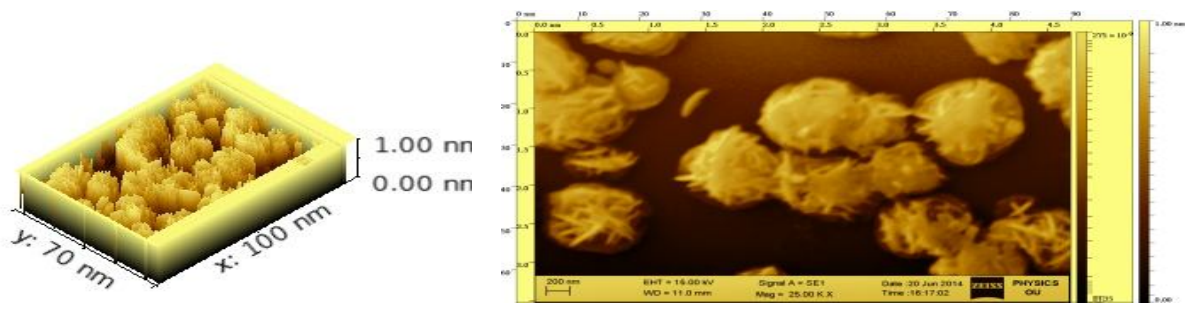

[a]

[b]

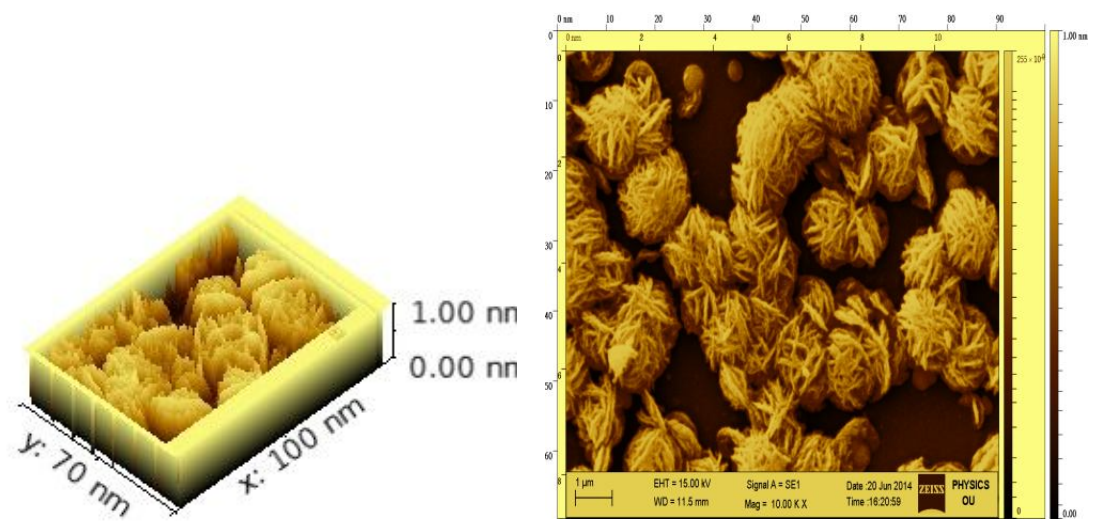

[c] 

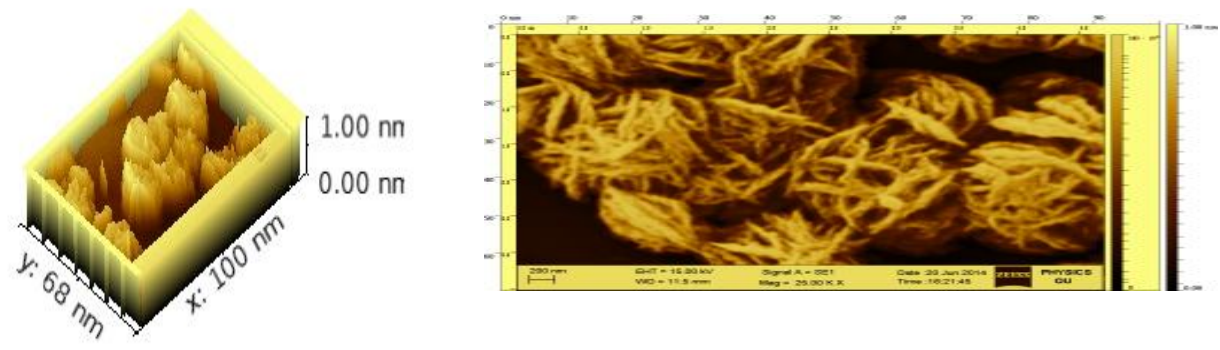

[e]

[f]

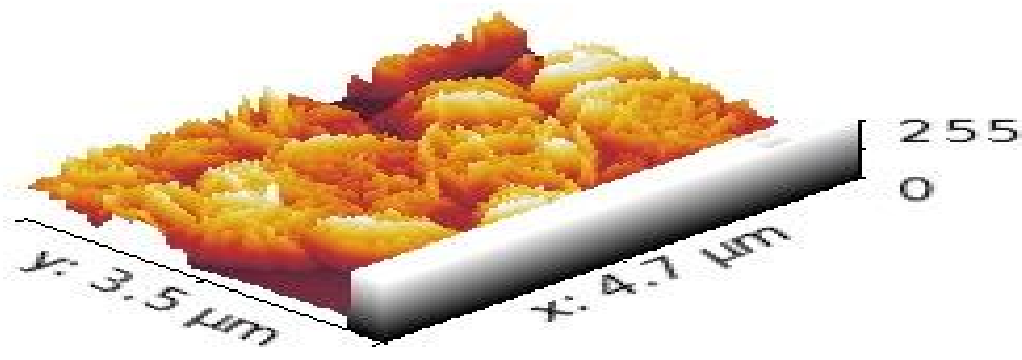

[g]

Figure 5: SEM Image of $\mathrm{SnS}$ thin films deposited on CBD at concentration of 0.1, 0.3 and $0.5 \mathrm{~m}$

\section{Surface morphology studies}

Figure 5: shows the scanning electron microscopy (SEM) Image of the 0.5m. This SEM nano graph reflects that the surface of the substrate was covered completely. The grains were distributed randomly over the surface of substrate. Threadworm-like grains are uniformly 
distributed over the surface. The sizes of the grains exhibit random orientation as it varies from one to another, which is in the range $200 \mathrm{~nm}$.

Table 4: shows the Rms surface roughness and grain size of different samples

\begin{tabular}{|l|l|l|l|}
\hline S. no. & Concentration & Grain size [nm] & $\begin{array}{l}\text { Rms Surface } \\
\text { roughness[nm] }\end{array}$ \\
\hline 1 & 0.1 & 68 & 5.7 \\
\hline 2 & 0.3 & 70 & 5.8 \\
\hline 3 & 0.5 & 255 & 8.3 \\
\hline
\end{tabular}

Fig 6 : RMS ROUGHNESS OF DIFFERENT CONCENNTRATIONS

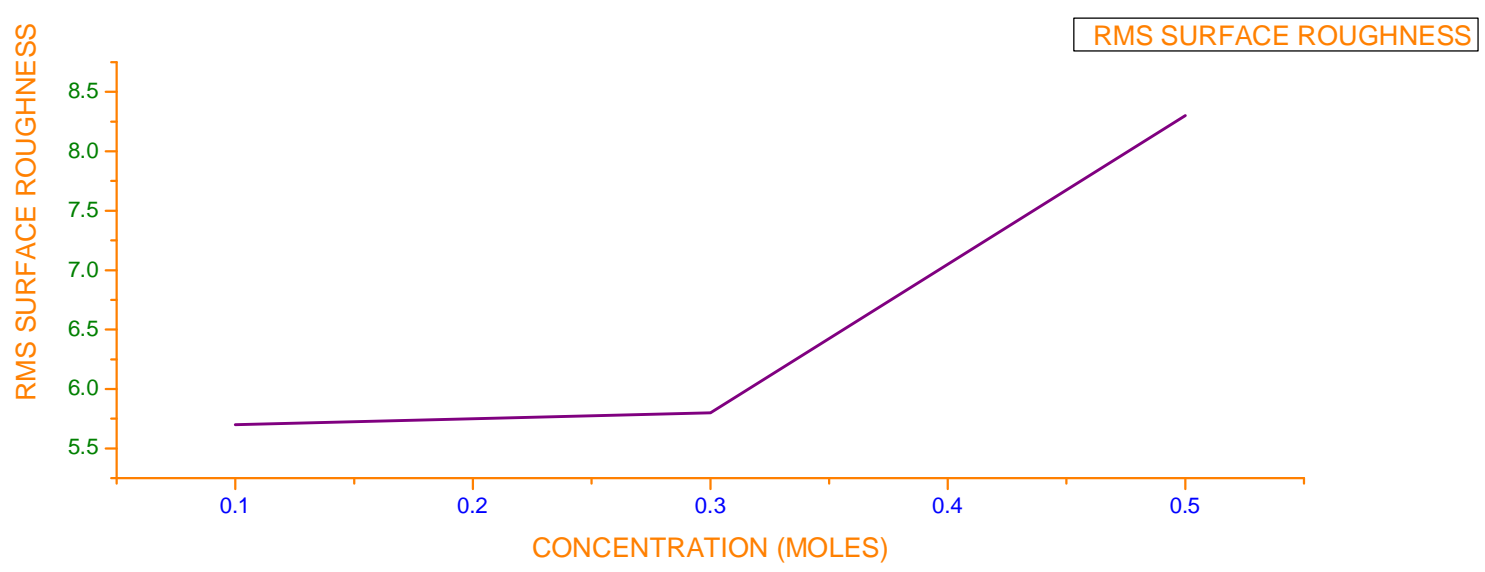

Figure 6 shows, Rms surface roughness increases very slowly till $03 \mathrm{~m}$ concentration. For the concentrations of $0.3 \mathrm{~m}$ to $0.5 \mathrm{~m}$ Rms surface roughness increases linearly 


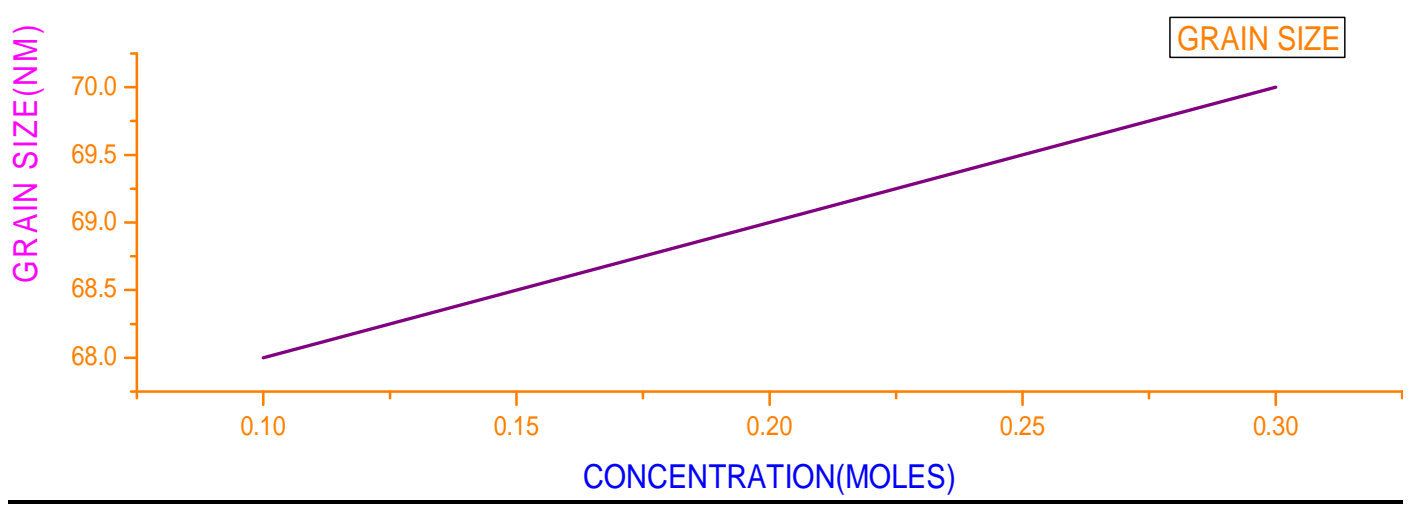

FIG 7: GRAINSIZE OF DIFFRENT CONCENTRATION SAMPLES

Fig 7 shows the increase in grain size with the increase in concentration

\section{ELECTRICAL PROPERTIES:}

All SnS Films of different concentrations on glass substrates exhibited P-type conductivity as confirmed by hot-point probe method. The measured resistivity $(\rho)$ of SnS films at room temperature shows large dependence on the concentration of the sample. The measured electrical resistivity for films deposited at different concentrations $(0.1,0.3$ and 0.5$)$ shows variation from $7.2 \times 10^{3}$ to $2.3 \times 10^{4} \Omega-\mathrm{cm}$. These observations show that $\mathrm{SnS}$ films have applications in design of photovoltaic and solar cells.

Table 5: Measured values of resistivity $(\rho)$ and conductivity $(\sigma)$ of $\operatorname{SnS}$ films with concentration

\begin{tabular}{|l|l|l|l|l|}
\hline S.no. & Concentration & Eg $(\mathbf{e v})$ & $\boldsymbol{\sigma}(\mathbf{\Omega} \cdot \mathbf{c m})-\mathbf{1}$ & $\boldsymbol{\rho}(\mathbf{\Omega} \cdot \mathbf{c m})$ \\
\hline 1 & 0.1 & 1.32 & $2.59 \times 10^{-6}$ & $7.2 \times 10^{3}$ \\
\hline 2 & 0.3 & 1.34 & $3.54 \times 10^{-5}$ & $8.2 \times 10^{3}$ \\
\hline 3 & 0.5 & 1.35 & $3.58 \times 10^{-4}$ & $2.3 \times 10^{4}$ \\
\hline
\end{tabular}

\section{CONCLUSIONS}

SnS thin films are polycrystalline in nature with an orthorhombic structure Tin chloride and thioacetamide were used as the sources of tin and sulphur respectively The resistivity of $\mathrm{SnS}$ thin film is about $6 \times 10^{4} \Omega \mathrm{cm}$, which is reasonably high for solar cell applications. However, it can be reduced by doping with suitable dopants.

\section{ACKNOWLEDGEMENTS}

We are grateful to Hyderabad Central University and Osmania University for providing laboratory facilities in making measurements of XRD and SEM

\section{REFERENCES}


[1]. M. T. S. Nair, C. Lop’ez-Mata, O. GomezDaza, and P. K. Nair,"Copper tin sulfide semiconductor thin films produced beheading $\mathrm{SnS}-\mathrm{CuS}$ layers deposited from chemical bath," Semiconductor Science and Technology, vol. 18, no. 8, pp. 755-759, 2003

[2]. Sajeesh TH, Sudha KC, Sanjeeviraja C, Abe T, Kashiwaba Y, Vijaykumar KP. Ex situ Sn diffusion: a wellsuited technique for enhancing the photovoltaic properties of a SnS absorber layer. JPhys D Appl Phys 2010; 43: 445102

[3]. B. Kherchachi., A. Attaf, H. Saidi, A. Bouhdjer, H. Bendjedidi, Y. Benkhetta, and R. Azizi Structural, optical and electrical properties of SnxSy thin films grown byspray ultrasonic Vol. 37, No3. 032001-6

[4]. P.S. Sonawane, P.A. Wani, L.A. Patil, T. Seth. Growth of CuBiS2 thin films by chemical bath deposition technique from an acidic bath, Materials Chemistry and Physics, Vol. 84, 221-227, 2004

[5]. Aarón Gómez1, Horacio Martínez2, Manuela Calixto-Rodríguez3, David Avellaneda4, Pedro Guillermo Reyes1and Osvaldo Flores2A Study of the Structural, Optical and Electrical Properties of SnS Thin Films Modified by Plasma Journal of Materials Science and Engineering B 3

[6]. (2013) 352 -358 (6)Bushra A. Hasan1,* and Ikhlas H. Shallal2 Structural and Optical Properties of SnS Thin Films J. Nano. Adv. Mat. 2, No. 2, $43-49$ (2014).

[7]. A Salem1, 2, S S Ahmed1,2,S N Almari.3 Structural and optical properties of nano crystalline Tin sulphide thin films deposited by thermal evaporation Indian journal of pure \&applied physics Vol 53, October 2015

[8]. Malkeshkumar Patel, Indrajit Mukhopadhyay, Abhijit Ray Annealing influence over structural and optical properties of sprayed SnS thin films Optical Materials 35 (2013) 1693-1699.

[9]. A Study of the Structural, Optical and Electrical Properties of SnS Thin Films Modified by Plasma PROPERTIES OF P-TYPE SnS THIN FILMS PREPARED BYCHEMICAL BATH DEPOSITION 